\title{
Context-dependent risks and benefits of transfusion in the critically ill
}

REVIEW

This article was published in the following Dove Press journal:

International Journal of Clinical Transfusion Medicine

30 March 2017

Number of times this article has been viewed

\author{
Yusrah Harahsheh ${ }^{1,2}$ \\ Kwok M Hol,3,4 \\ 'Department of Intensive Care \\ Medicine, Royal Perth Hospital, \\ ${ }^{2} S c h o o l$ of Medicine \& Pharmacology, \\ ${ }^{3}$ School of Population Health, \\ University of Western Australia, \\ ${ }^{4}$ School of Veterinary \& Life Sciences, \\ Murdoch University, Perth, WA, \\ Australia
}

Abstract: Transfusion of red blood cells (RBCs) and other blood products to critically ill patients is common. Blood products are expensive, and not without risks. Recent evidence from high-quality multicenter randomized controlled trials confirmed the safety of allogeneic $\mathrm{RBC}$ transfusions, including the use of aged RBCs, and mild to moderate anemia for most stable and nonbleeding critically ill patients. Emerging evidence suggests that a liberal RBC transfusion target may have potential divergent effects on patient outcomes depending on their clinical context, with possible harms for patients with gastrointestinal bleeding due to portal hypertension and, conversely, benefits for patients with severe underlying cardiovascular diseases. Despite an apparent increased risk of bleeding in critically ill patients with deranged coagulation parameters and thrombocytopenia, recent studies suggested that fresh frozen plasma (FFP) and platelet transfusions may not be beneficial and, indeed, also not very effective in correcting these abnormalities. As for patients who have active severe critical bleeding, use of empirical 1:1:1 RBC: platelets: FFP transfusion appears justifiable in an attempt to reduce deaths as a result of exsanguination. In conjunction with platelet count and fibrinogen concentration, whole blood viscoelastic and platelet function tests are particularly useful to assist clinicians to rationalize FFP and platelet transfusions, when imminent death from exsanguination is not anticipated. Because the risks and benefits of blood product transfusion are heavily context-dependent, a thorough consideration of the characteristics and clinical status of the patients, in conjunction with viscoelastic and platelet function tests, is needed to rationalize the decision to transfuse (or withhold) blood products - very much in line with the move toward the practice of individualized or personalized medicine.

Keywords: red blood cells, fresh frozen plasma, platelets, critical illness

\section{Introduction}

English physician William Harvey discovered the circulation of blood in 1628, and by 1665, physician Richard Lower recorded the first successful use of blood transfusion to keep dogs alive by transfusing blood from other dogs. ${ }^{1}$ The first successful blood transfusion in a human was recorded in 1818 for a woman with postpartum hemorrhage using her husband's blood, before major blood groups were known and the associated danger of transfusing mismatched blood was considered. ${ }^{2}$ In 1900, Karl Landsteiner, an Austrian physician, discovered the first three human blood groups, A, B, and C; and $\mathrm{C}$ was later changed to $\mathrm{O} .{ }^{3}$ His colleagues Alfred von Decastello and Adriano Sturli added group AB, the fourth type, in $1902 .{ }^{4}$ Landsteiner received the Nobel Prize for Medicine for this discovery in 1930. ${ }^{1}$ Since then, red blood cells (RBCs) and other blood products, including fresh frozen plasma (FFP) and platelets, have been widely
Correspondence: Yusrah Harahsheh Department of Intensive Care Medicine, Royal Perth Hospital, Wellington Street, Perth, WA 6000, Australia

Tel +6I 892241056

Fax +6I 892243668

Email yusra.harahsheh@health.wa.gov.au
International Journal of Clinical Transfusion Medicine 2017:5 29-37 (c) (7) (5) 2017 Harahsheh and Ho. This work is published and licensed by Dove Medical Press Limited. The full terms of this license are available at https://www.dovepress.com/terms. BY NC php and incorporate the Creative Commons Attribution - Non Commercial (unported, v3.0) License (http:///(creativecommons.org/licenses/by-nc/3.0/). By accessing the work you hereby accept the Terms. Non-commercial uses of the work are permitted without any further permission from Dove Medical Press Limited, provided the work is properly attributed. For permission for commercial use of this work, please see paragraphs 4.2 and 5 of our Terms (https://www.dovepress.com/terms.php). 
used for major bleeding, anemia, and a variety of hematological disorders.

Appropriate use of blood products is vital to optimize patient outcomes. In the past two decades, patient blood management programs have been developed in many health care institutions to improve blood product utilization and, when feasible, use alternatives to allogeneic blood products and methods to minimize blood loss. ${ }^{5}$ Although many patient blood management programs have been successful in reducing unnecessary or inappropriate use of blood products, allogeneic blood product transfusion remains widely used for many hospitalized patients, particularly for those in the intensive care unit (ICU). Earlier epidemiological studies showed that up to $45 \%$ of critically ill patients had allogeneic RBC transfusions during their ICU stay. ${ }^{6,7}$ In the latest audit of our critically ill patients, up to $27 \%$ of the ICU patients still received allogeneic $\mathrm{RBC}$ transfusions, especially common in those with multiple organ failure, despite adopting a restricted transfusion protocol. ${ }^{8}$ Similarly, FFP (30\%) and platelet $(23 \%)$ transfusions remain common in the critically ill. ${ }^{9,10}$ The findings of these epidemiological studies are not entirely surprising, because for better or worse, the clinical intuition to correct severely deranged physiology, such as anemia, or coagulation parameters before invasive procedures for someone who is also unwell in many other ways, is compelling..$^{9-11}$

Numerous studies assessing the benefits and risks of RBC and blood product transfusions have been published in the past few decades, but which and when patients should receive allogeneic blood products remain contentious and uncertain. The dilemma of "To be (or transfuse), or not to be (or transfuse)..." is a major daily conundrum for all intensivists. In this narrative review, we aim to summarize the potential benefits and risks of RBCs and other blood products in the critically ill. Whether a certain blood product should be used, or its risk to benefit ratio, is likely to vary substantially depending on the characteristics and circumstances of the patients - similar to moving the position of a fulcrum of a balance (Figure 1). ${ }^{11}$ In contemplating to reduce allogeneic blood product utilization, we should also consider the associated risks and costs of the alternatives before we can formulate the best transfusion or patient blood management strategy for each individual critically ill patient. ${ }^{12}$ While erythropoietin and intravenous iron are widely used to reduce allogeneic RBC transfusions for patients with chronic renal failure, evidence to support their use in the critically ill remains sparse. The limitations of these two alternatives to allogeneic RBC transfusions are summarized in Table $1 .{ }^{12-19}$

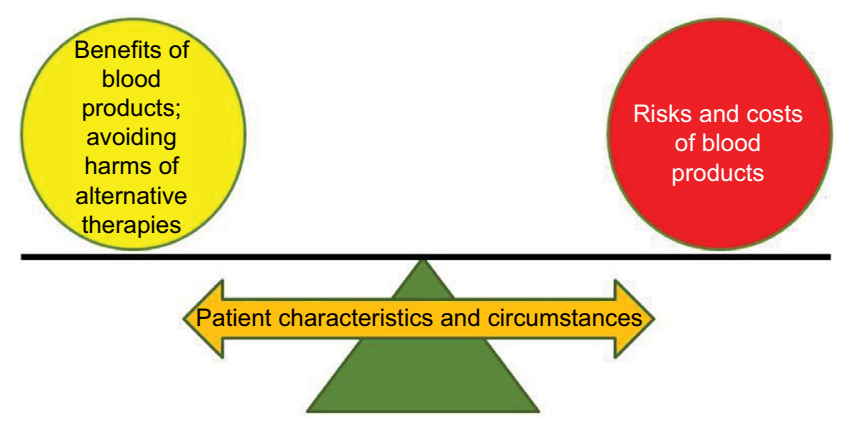

Figure I The importance of patient's context in balancing the risks and benefits of allogeneic red blood cell and blood product transfusions.

Table I Limitations of erythropoietin and intravenous iron in the critically ill

Erythropoietin

I. No level I evidence to suggest that it could reduce allogeneic RBC transfusions, which may be due to the presence of iron and/or vitamins restricted erythropoiesis in the critically ill

2. Increased risk of thrombotic vascular events ( $5 \%$ increase in absolute risk), pyrexia (18\%), hypokalemia (15\%), and hypophosphatemia (I5\%)

3. No reliable clinical or laboratory predictors can be used to identify critically ill patients who would respond to erythropoietin

4. Cost of epoetin-alpha is $>$ US $\$ 900$ per per 40,000 units

Intravenous iron

I. No significant effect in reducing risk or number of units of allogeneic RBC transfusions (iron sucrose $100 \mathrm{mg}$ intravenous or placebo thrice weekly for up to 2 weeks or $500 \mathrm{mg}$ of ferric carboxymaltose and repeat $\geq 4$ days beyond their previous dose if hemoglogbin $<100 \mathrm{~g} / \mathrm{L}$ and ferritin level $<1,200 \mathrm{ng} / \mathrm{mL}$ and transferrin saturations $<50 \%$ )

2. No reliable clinical or laboratory predictors, including serum hepcidin concentration, can be used to identify critically ill patients who would respond to intravenous iron

3. Known side effects include nausea (3.1\%), hypophosphatemia (I.9\%), injection-site reactions ( $1.6 \%)$, headache ( $1.4 \%$ ), hypertension (I.3\%), dizziness (1.2\%), and possibly infection

4. Cost of ferric carboxymaltose $500 \mathrm{mg}$ is $>$ US $\$ 200$

Abbreviation: RBC, red blood cell.

\section{Benefits and risks of RBC transfusions in the critically ill Overall evidence from large multicenter randomized controlled trials (RCTs)}

Numerous observational studies have demonstrated that allogeneic RBC transfusions were associated with worse clinical outcomes - including a dose-related relationship in a variety of patient populations. ${ }^{6,20}$ Similarly, transfusion of aged RBCs has also been reported to be associated with worse clinical outcomes in many observational studies. ${ }^{21}$ It is important to emphasize that despite vigorous statistical adjustment, residual confounding remains a major threat to the internal validity of any observational studies - even when a dose-related relationship is demonstrated..$^{22}$ As such, a strong conclusion about the benefits and risks of $\mathrm{RBC}$ 
transfusions cannot, and should not, be drawn solely from the results of observational studies.

To the best of our knowledge, there were at least three large multicenter RCTs comparing liberal vs restricted RBC transfusion strategies in the critically ill, nonbleeding, adult, and pediatric patients. All three studies did not demonstrate superiority of targeting a higher hemoglobin concentration (or avoiding anemia) in improving mortality or organ failure ( $\mathrm{N}=838$ adult general ICU patients: 7-9 vs $10-12 \mathrm{~g} / \mathrm{dL}$; $\mathrm{N}=637$ pediatric ICU patients: 7 vs $9.5 \mathrm{~g} / \mathrm{dL}$; $\mathrm{N}=998$ adult septic shock patients: 7 vs $9 \mathrm{~g} / \mathrm{dL}) .{ }^{23-25}$ The results of these RCTs suggest that mild to moderate anemia is well tolerated in many nonbleeding critically ill patients or, alternatively, any probable benefits of RBC transfusions are counteracted by its potential harms. Similarly, RCTs also could not demonstrate adverse effects of aged RBC transfusions on mortality or organ failure compared to fresh $\mathrm{RBC}$ transfusions. ${ }^{26,27}$ Although using allogeneic RBC transfusions to achieve a hemoglobin target of $>9 \mathrm{~g} / \mathrm{dL}$ appears to be relatively safe for most critically ill patients, this does not imply allogeneic RBCs are totally safe for all critically ill patients.

\section{Risks of a liberal RBC transfusion strategy}

In a moderate size factorial-designed RCT assessing the effects erythropoietin and different transfusion thresholds for patients with traumatic brain injury, targeting a higher hemoglobin concentration not only made no improvement in patients' 6-month neurological outcomes $(\mathrm{N}=200,7$ vs $10 \mathrm{~g} / \mathrm{dL}$ ), but was also associated with a higher incidence of venous thromboembolism $(21.8 \%$ vs $8.1 \%) .{ }^{28}$ In another interesting large single-center Spanish RCT $(\mathrm{N}=921)$, targeting a higher hemoglobin concentration $(9 \mathrm{~g} / \mathrm{dL})$ in patients with upper gastrointestinal bleeding was associated with an increased risk of rebleeding and 6-week mortality compared to accepting a lower hemoglobin target $(7 \mathrm{~g} / \mathrm{dL}) .{ }^{29}$ On detailed examination of this study, the associations between transfusion and adverse outcomes were predominantly explained by the worse outcomes of the patients with Child-Pugh class $\mathrm{A}$ and $\mathrm{B}$ cirrhosis who were allocated to liberal transfusion group (hazard ratios for mortality and rebleeding $>1.8$ and 3.0 , respectively). In the subgroup of patients with hepatic hemodynamic measurements repeated $(n=151)$, the portalpressure gradient only increased significantly in patients allocated to the liberal transfusion strategy $(p=0.03)$ but not in those allocated to the restrictive strategy. The liberal transfusion group had on average 2.2 units RBC transfusions more compared to the restricted group in addition to a similar total amount of other intravenous fluids, including crystalloids, colloids, and other blood products. This result suggests that there was likely an element of hypervolemia in the liberal transfusion group, which could have contributed to an increase in portal hypertension - resulting in an increased risk of rebleeding and mortality. ${ }^{29}$

It is possible that the danger of liberal transfusion and hypervolemia is only restricted to patients with variceal bleeding, and not with all causes of gastrointestinal bleeding. A recent multicenter study from the UK also assessed the benefits and harms of targeting different hemoglobin levels in patients with gastrointestinal bleeding. ${ }^{30}$ The case-mix of this study was, however, very different from the Spanish study discussed earlier. When variceal bleeding is not the dominant cause of gastrointestinal bleeding, as in the UK study $(9 \%, 81$ out of 936$)$, a liberal transfusion strategy (10 $\mathrm{g} / \mathrm{dL}$ ) was not associated with different clinical outcomes, including 28 -day mortality (7\% in the liberal vs $5 \%$ in the restricted group), compared to a more restricted transfusion target $(8 \mathrm{~g} / \mathrm{dL}) .{ }^{30}$ As such, depending on the underlying cause of gastrointestinal bleeding, it is biologically plausible for a liberal RBC transfusion strategy to have diverse effects on patient outcomes compared to a restricted strategy even between different patients with gastrointestinal bleeding.

\section{Risks of a restricted RBC transfusion strategy}

Knowing liberal transfusions may be harmful for some subgroups of critically ill patients leads us to ask the logical question of whether a restricted transfusion strategy may also be harmful for some other subgroups of patients. Physiologically, hemoglobin concentration is the main determinant of oxygen-carrying capacity of the blood, and anemia is tolerated provided systemic oxygen delivery is maintained by a higher cardiac output. For patients who have inadequate physiological reserve to increase their cardiac output, it is possible for moderate anemia to compromise the systemic oxygen delivery. In clinical practice, the decision to transfuse a stable nonbleeding patient relies on the comprehensive assessment of the patient's condition, which does not occur for a similar patient enrolled in a RCT comparing different transfusion thresholds. The misalignment between the level of therapy and the severity of illness of the patient hinders the translation of RCTs' results to everyday clinical practice, ${ }^{11}$ where the relationship is preserved for patients with severe underlying cardiovascular diseases. ${ }^{31}$ The possible effect of misalignment between patients' condition and therapy tested in an RCT on generalizing large multicenter RCTs' results to 
all patient subgroups can be further illustrated by the results of a recent RCT and two meta-analyses on perioperative transfusion. ${ }^{32-34}$

A Brazilian single-center RCT $(\mathrm{N}=198)$ reported that using a liberal transfusion target $(9 \mathrm{~g} / \mathrm{dL})$ for surgical oncology patients was associated with a lower risk of mortality and postoperative complications than a more restricted transfusion target $(7 \mathrm{~g} / \mathrm{dL}$ ) (absolute risk reduction in the composite end point of all adverse outcomes $16 \%$, 95\% confidence interval $[\mathrm{CI}]$ : $3.8-28.2) .{ }^{32}$ Why moderate anemia with a restricted transfusion target is not well tolerated for some surgical oncology patients is unclear, but it is possible that the physiological reserve of these cancer patients is already substantially compromised by the underlying cancers and/ or the associated chemo- or radiotherapy. In a meta-analysis of nine RCTs enrolling patients with cardiovascular diseases $(\mathrm{N}=2,609)$ who underwent major noncardiac surgery, the risk of acute coronary syndrome in patients managed with restricted transfusion target $(<8 \mathrm{~g} / \mathrm{dL})$ was significantly higher than those managed with a liberal transfusion target $(>8 \mathrm{~g} / \mathrm{dL})$ (relative risk 1.8, 95\% CI: $1.3-2.7, p=0.01, \mathrm{I}^{2}=0 \%$ ). ${ }^{33} \mathrm{In}$ another meta-analysis including $31 \mathrm{RCTs}$ on adult surgical and critically ill patients, the benefits of allogeneic RBC transfusions were shown to be context-dependent, with a reduced risk of mortality and composite morbidity after using liberal transfusion only in higher risk patients including those who underwent cardiac/vascular procedures and elderly orthopedic patients. ${ }^{34}$ Under normal circumstances, myocardial oxygen extraction is at its maximal capacity and any reductions in oxygen carrying capacity caused by anemia are compensated by an increase in coronary blood flow. In patients with coronary artery diseases, an increase in coronary artery flow is not feasible and hence it is possible for moderate anemia to induce myocardial ischemia which may explain the findings of these two meta-analyses. ${ }^{33,34}$ As such, an individualized approach to allogeneic RBC transfusions is advisable for patients who are at high risk of developing myocardial ischemia in order to maximize its benefits and minimize its harms.

\section{Evidence from observational and experimental studies}

While RCTs assessing transfusion thresholds on stable nonbleeding critically ill and perioperative patients are abundant, similar RCTs on bleeding patients are scarce - in part due to ethical considerations in conducting such studies. In line with the discussion above about the interactions between benefits of allogeneic RBC transfusions and risk-context of the patients, observational data from the secondary analysis of the CRASH-2 trial showed that allogeneic RBC transfusions were associated with an increase in all-cause mortality among patients with $<6 \%$ and $6 \%-20 \%$ predicted risk of death (odds ratio [OR]: 5.4, 95\% CI: 4.1-7.1, $p<0.0001$; and OR: 2.3, 95\% CI: $2.0-2.7, p<0.0001$, respectively), but an opposite effect of transfusion on mortality was observed for patients with $>50 \%$ predicted risk of death (OR: $0.6,95 \%$ CI: $0.5-0.7$, $p<0.0001) .{ }^{35}$ The possible survival benefit of allogeneic $\mathrm{RBC}$ transfusions in traumatic hemorrhage is, in part, supported by a simulation study showing that hemoglobin concentration (or hematocrit) has a substantial effect on platelet dynamics. A higher hematocrit can improve margination of platelets closer to the vessel wall where hemostasis normally occurs after tissue injury. ${ }^{36}$ Recent experimental evidence also suggests that RBCs are essential in forming an impermeable complex polyhedral structure blood clot to optimize hemostasis. ${ }^{37,38}$

Although maintaining a higher hematocrit may be beneficial for patients with active critical bleeding requiring massive transfusion, the side effects and complications of allogeneic RBC transfusions are also amplified in this setting. As such, any potential benefits of maintaining a certain hematocrit must be balanced against the complications and costs of massive RBC transfusions, ${ }^{39,40}$ as both the rate and quantity of RBC transfusions would increase the incidence and severity of these complications. The possible benefits and risks of allogeneic RBC transfusions are summarized in Table 2.

\section{Benefits and risks of platelet transfusions in the critically ill}

According to the cell-based coagulation model, platelets are an essential element in the activation of the coagulation factors as well as the formation of a blood clot. ${ }^{41,42}$ The liberal use of platelets (together with FFP) in critical bleeding was supported initially by a validation study of 10 patients presenting with severe uncontrolled bleeding, demonstrating that such strategy resulted in normal in vitro clot strength in all patients, including those who had received over $15 \mathrm{~L}$ of blood products. ${ }^{43}$ A before-and-after study on patients with ruptured abdominal aortic aneurysm showed that a high ratio of empirical platelet (and FFP) to RBC transfusions was associated with an improved 30-day survival compared to using the traditional laboratory parameters guided transfusion strategy. ${ }^{44}$ A recent multicenter RCT $(\mathrm{N}=680)$ also showed that using a higher proportion of platelets with FFP to $\mathrm{RBCs}$, in a 1:1:1 ratio approach, could improve anatomic hemostasis and reduce deaths as a result of exsanguination 
Table 2 Theoretical benefits and risks of RBC transfusions

Potential benefits:

I. Increased oxygen delivery to vital organs including the heart in patients with coronary artery disease; volume transfused (in milliliter $)=$ expected hemoglobin rise $(\mathrm{g} / \mathrm{dL}) \times$ body weight (in kilogram) $\times 3$

2. A higher hematocrit may be needed for optimal clot strength and enhancing margination of platelets to the vessel wall in critical bleeding

Potential risks:

I. Excessive intravascular volume (sometimes referred as transfusionassociated circulatory overload)

2. Dilution of circulatory clotting factors, albumin concentration, and platelet count

3. Acute and delayed hemolytic transfusion reactions and RBC alloimmunization (production of irregular antibodies against RBC antigens other than $A B O$ blood group related antigens)

4. Allergic nonhemolytic reactions including febrile response and urticaria

5. Rhesus $D$ antigen sensitization is very rare because of routine pretransfusion $D$ antigen testing of recipients

6. Hypothermia (if the blood is not warmed by a blood warmer)

7. Citrate toxicity (risk with FFP > whole RBC unit > packed RBC unit; increased risk in hypothermic patients, hepatic dysfunction, or rapid transfusion: a normal liver can metabolize $3 \mathrm{~g}$ of citrate every 5 minutes, and each packed RBC unit contains $0.5-3 \mathrm{~g}$ of citrate, depending on the type of additive solution used)

8. Hyperkalemia (in rapid transfusion)

9. Acute lung injury within 6 hours of transfusion or also called "transfusion-related acute lung injury" (risk < FFP)

10. Venous thromboembolism in patients with traumatic brain injury when a high hemoglobin concentration is targeted $(\mathrm{eg}, 10 \mathrm{~g} / \mathrm{dL}$ vs $7 \mathrm{~g} / \mathrm{dL}$ )

II. Bacterial contamination

I2. Blood-borne infections (HIV: I in 2 million, Hepatitis B: I in 205,000, and Hepatitis C: I in 2 million)

13. Iron overload (for repeated transfusions)

14. Graft-versus-host disease in severely immunocompromised patients due to transfused white blood cells, in particular T-lymphocytes, in the RBC unit (each RBC unit of contains on average $0.32 \times 10^{6}$ white blood cells; this complication can be prevented by $\gamma$-irradiated the allogeneic RBCs prior to transfusion)

15. The average cost of a unit of packed RBCs is >US $\$ 200$.

Abbreviations: FFP, fresh frozen plasma; RBC, red blood cell.

within the first 24 hours of trauma admission. ${ }^{45}$ The findings from these studies suggested that empirical platelet transfusion may improve outcomes and should be seriously considered for patients with active critical bleeding requiring massive transfusion.

Although platelets are important in optimizing hemostasis in critical bleeding, the same cannot be extended to other critically ill patients who have asymptomatic thrombocytopenia including those who are going to subject to an invasive procedure. Because platelet transfusion is expensive and not without risks (Table 3), ${ }^{46-48}$ careful selection of nonbleeding patients who would benefit from platelet transfusion is
Table 3 Theoretical benefits and risks of platelet transfusions

Potential benefit:

I. Increase in platelet count (each pool of platelets [containing $351 \times 10^{9}$ platelets in $340 \mathrm{~mL}$ ] given is expected to increase platelet count by at least $15 \times 10^{9} / \mathrm{L}$ in an adult patient or an increase platelet count (in $10^{9} / \mathrm{L}$ ) $=2 \mathrm{I} /$ body surface area in children) which is vital in the activation of the coagulation factors and formation of blood clot according to the cell-based coagulation model; the absolute increase in platelet count post platelet transfusion depends on $A B O$ matching, storage duration of the platelet unit and recipient's characteristics

Potential risks:

I. Hemolytic reactions with a positive direct antiglobulin test when the donor and recipient are $A B O$ mismatched due to anti-A and anti- $B$ antibodies in the transfused platelet units (eg, group $O$ platelets to group $A, B$, or $A B$ recipients)

2. Allergic nonhemolytic reactions including urticaria and fever

3. Immunomodulatory, proinflammatory, and prothrombotic tendency including possible increased risk of thromboembolism in the critically ill and also situations with increased platelet destruction such as heparin-induced-thrombocytopenic syndrome and thrombotic thrombocytopenia purpura

4. Bacterial contamination (risk $>$ RBCs due to the fact that platelets are stored under continuous agitation at about $22^{\circ} \mathrm{C}$ for up to 5 days)

5. Transfusion-related acute lung injury (risk $<$ fresh frozen plasma)

6. Red blood cells alloimmunization sensitization

7. Graft-versus-host disease in severely immunocompromised patients due to transfused white blood cells in particular T-lymphocytes in the platelets (mean white blood cell count in a pooled platelet unit is $<0.01 \times 10^{6}$ and hence the risk of this complication is less than after RBC transfusions)

8. Cost of a pooled platelet unit $>$ US $\$ 500$

Abbreviation: $\mathrm{RBC}$, red blood cell.

required. While there are data from RCTs to support the use of platelet transfusion for severe chemotherapy-associated thrombocytopenia $\left(<10 \times 10^{9} / \mathrm{L}\right),{ }^{49,50}$ there is no evidence to support empirical platelet transfusion in critically ill patients with thrombocytopenia alone, without active bleeding, would improve patient outcomes. Indeed, platelet transfusions in the setting of hemorrhagic stroke, while taking an antiplatelet agent, were associated with an increased risk of mortality or dependence at 3 months (adjusted OR: 2.1, 95\% CI: 1.2-3.6; $p=0.01$ ), consistent across all predefined subgroups, and remained so after adjusting for potential confounders. ${ }^{51}$ While this adverse association could be spurious, and may have occurred purely by chance (due to the small sample size of the study), there is also a biological plausibility for platelet transfusions to induce harms, including increased risk of thromboembolism $(4 \% \text { vs } 1 \%, p=0.17)^{51}$ or potentiation of proinflammatory response. ${ }^{46}$ At the very least, withholding "empirical" platelet transfusion in the setting of antiplatelet therapy-associated intracerebral hemorrhage appears to be safe.

Recent studies suggest that platelet function tests may be useful in predicting blood loss and guiding platelet 
transfusion in patients undergoing major surgery including cardiac surgery. ${ }^{52,53}$ As we move toward the age of practicing individualized or personalized medicine, the ability to quantify platelet function for each individual patient on a real-time basis has a great potential to assist clinicians to rationalize their decision in platelet transfusion for nonbleeding critically ill patients, beyond empirically or using platelet count alone. ${ }^{54}$

Currently there are many different methods to measure platelet function, including tests that assess the effect of platelet aggregation on electrical impedance (eg, Multiplate ${ }^{\circledR}$ Analyzer; Roche Diagnostics Limited, Rotkreuz, Switzerland]), or photo-transmission, and platelet adhesion under shear stress (eg, Innovance ${ }^{\circledR}$ PFA-200 System; Siemens Healthcare Pty Ltd, Bayswater, VIC, Australia). In addition to documenting the presence of platelet dysfunction, some platelet function tests also have the capacity to quantify the severity of platelet dysfunction or degree of inhibition by antiplatelet drugs by using different platelet activators, such as arachidonic acid, adenosine diphosphate, or thrombin receptor-activating peptide, allowing clinicians to determine whether any ongoing bleeding is influenced by a residual effect of antiplatelet therapy in a patient-specific or individualized fashion. Clinicians should, however, be aware that thrombocytopenia may produce a platelet function test result similar to platelet dysfunction or inhibition by antiplatelet agents. As such, all platelet function test results must be interpreted simultaneously with the platelet count. The utility and limitations of using platelet function and whole blood viscoelastic point-of-care (VE-POC) tests to guide platelet transfusion in critical bleeding are described in detail in our recent review. ${ }^{42}$

\section{Benefits and risks of FFP transfusions in the critically ill}

Similar to platelets, as part of 1:1:1 transfusion strategy to prevent dilutional coagulopathy FFP is increasingly used in critical bleeding. ${ }^{45}$ Because FFP is associated with a significant number of side effects (Table 4), in particular transfusion-related acute lung injury, ${ }^{55}$ recent studies have explored the possibility of using empirical fibrinogen concentrate or cryoprecipitate to replace FFP in critical bleeding. ${ }^{56,57}$ Indeed, plasma fibrinogen concentration appears to be first coagulation factor to be depleted in trauma-acquired coagulopathy ${ }^{58}$ RCTs on early use of fibrinogen concentrate $(60-70 \mathrm{mg} / \mathrm{kg})$ in trauma- or surgery-induced hemorrhage are already under way, ${ }^{59,60}$ and if the results are positive, a reduction in the usage of FFP in critical bleeding is anticipated.
Table 4 Theoretical benefits and risks of FFP transfusions

Potential benefits:

I. Increase coagulation factor levels in the blood in patients with deficiency in a wide range of coagulation factors

2. Replenish ADAMTSI 3 as part of plasmapheresis therapy for thrombotic thrombocytopenia purpura

3. Replace factor $V$ deficiency, factor $X$ deficiency, factor XI deficiency, $\mathrm{Cl}$ esterase inhibitor deficiency (hereditary angioedema) when specific factor concentrates are not available

4. To replace factor VII when combined with Prothrombinex ${ }^{\circledR}$-VF (containing mainly factor II, IX, and X) to reverse warfarin; FFP is not necessary if prothrombin complex concentrate is used as it contains all four vitamin K-dependent coagulation factors

5. Improve endothelial glycocalyx structure and function compared to crystalloids or hydroxyethyl starch in hemorrhagic shock

Potential risks:

I. Excessive intravascular volume (sometimes referred as transfusionassociated circulatory overload)

2. Hypothermia

3. An FFP to packed RBCs ratio $>1.5$ would lead to dilutional anemia and thrombocytopenia

4. Hemolysis if $A B O$ blood groups not compatible (eg, group O FFP to group $A, B$, or $A B$ recipients)

5. Allergic reactions (type I hypersensitivity to plasma proteins)

6. Citrate toxicity (risk > platelets or packed RBCs transfusion as each unit of FFP contains about I $g$ of citrate, between 2-4 times more citrate than in each unit of packed RBCs)

7. Transfusion-related acute lung injury (risk $>R B C s$ or platelets transfusion)

8. Cost of a unit of FFP $>$ US $\$ 60$

Abbreviations: FFP, fresh frozen plasma; RBC, red blood cell.

In addition to critical bleeding, FFP is also often misused to correct abnormal coagulation blood tests in the critically ill without clinical bleeding. ${ }^{9}$ Recent studies suggested that abnormal coagulation blood tests including an elevated international normalized ratio or activated partial thromboplastin time are common in the critically ill, ${ }^{9,61,62}$ and administration of FFP is neither effective in correcting these abnormal coagulation results nor necessarily able to prevent clinical bleeding. ${ }^{62,63}$ Whole blood VE-POC tests, including thromboelastography (Teg ${ }^{\circledR}$; Haemonetics ${ }^{\circledR}$, Braintree, MA, USA) and rotational thromboelastometry (Rotem ${ }^{\circledR}$; The Tem Group, Basel, Switzerland), are increasingly used to guide FFP (and other blood products) transfusion in the perioperative and critical care settings. This strategy appears to be both safe and more cost-effective than empirically correcting abnormal coagulation results in patients undergoing surgery or invasive procedures ${ }^{63,64}$ That said, clinicians should also be aware of the limitations of VE-POC tests in reflecting in vivo hemostasis. ${ }^{42}$

Finally, preliminary evidence suggests that FFP may also have benefits beyond replacing the coagulation factors, including stabilizing the glycocalyx of endothelium in hemorrhagic shock and nonbleeding critically ill patients. ${ }^{65-68}$ 
Whether the benefits of FFP on endothelial function will outweigh its risks remains uncertain, but this merits further investigation by adequately powered RCTs.

\section{Conclusion}

Although RBCs and other blood products are relatively safe, they are also expensive and not without risks. In contemplating strategies to reduce allogeneic RBC transfusions, the risks and costs of alternative therapies, such as intravenous iron, should also be considered. Evidence from high-quality RCTs showed that mild to moderate anemia ( $>7 \mathrm{~g} / \mathrm{dL})$ is well-tolerated by most critically ill nonbleeding patients. In patients with significant underlying cardiovascular disease or active bleeding - especially critical bleeding - maintaining a higher hemoglobin target by allogeneic blood transfusion may be warranted after careful consideration of the clinical context of the patients. It should be noted that maintaining a high hemoglobin concentration $(>10 \mathrm{~g} / \mathrm{dL})$ after traumatic brain injury by erythropoietin and allogeneic transfusion may indeed increase the risk of venous thromboembolism. In addition, a liberal transfusion strategy may lead to hypervolemia, which could be harmful for patients with gastrointestinal bleeding from portal hypertension.

In patients with severe critical bleeding, recent evidence suggested that transfusion strategy with a higher platelet and FFP to RBCs ratio may reduce deaths from exsanguination. This does not mean that platelets and FFP should be used to correct asymptomatic thrombocytopenia and abnormal coagulation blood tests in stable nonbleeding critically ill patients. Use of platelet function and VE-POC tests may be particularly helpful to rationalize platelet and FFP transfusions in critically ill patients who have no active critical bleeding and possibly also before invasive procedures. Whether the potential benefits of FFP on endothelial function could justify its role beyond replacing coagulation factors in hemorrhagic shock is unknown, and this merits further investigation by adequately powered RCTs.

In summary, the risks and benefits of RBC and blood product transfusions in the critically ill are heavily contextdependent; a thorough consideration of the characteristics and clinical status of the patients, in conjunction with platelet function and VE-POC tests, is pivotal to rationalize each decision to transfuse blood products - very much in line with the move toward practicing individualized or personalized medicine. "The more the better" certainly does not apply to transfusion practice in the intensive care - or at least not for most stable and nonbleeding critically ill patients.

\section{Acknowledgment}

Dr Ho would like to thank the WA Health and Raine Medical Research Foundation for their support through the Raine Clinical Research Fellowship.

\section{Disclosure}

The authors report no conflicts of interest in this work.

\section{References}

1. American Association of Blood Bank [homepage on the Internet]. Highlights of Transfusion Medicine History. Available from: http:// www.aabb.org/tm/Pages/highlights.aspx. Accessed February 6, 2017.

2. Blundell J. Experiments on the transfusion of blood by the syringe. Med-Chir Trans. 1818;9(Pt 1):56-92.

3. Landsteiner K. Zur Kenntnis der antifermentativen, lytischen und agglutinierenden Wirkungen des Blutserums und der Lymphe [Antienzymatic, lytic, and agglutinating properties of blood serum and lymph]. Centralblatt für Bacteriologie. 1900;27:357-362. German.

4. von Decastello A, Sturli A. Ueber die Isoagglutinine im Serum gesunder und kranker Menschen [On the isoagglutinins in the serum of healthy and sick persons]. Mfinch med Wschr. 1902;49:1090-1095. German.

5. Society for the Advancement of Blood Management. Professional Definition: Patient Blood Management. Available from: http://www. sabm.org/. Accessed March 8, 2017.

6. Corwin HL, Gettinger A, Pearl RG, et al. The CRIT Study: Anemia and blood transfusion in the critically ill--current clinical practice in the United States. Crit Care Med. 2004;32(1):39-52.

7. Vincent JL, Baron JF, Reinhart K, et al; ABC (Anemia and Blood Transfusion in Critical Care) Investigators. Anemia and blood transfusion in critically ill patients. JAMA. 2002;288(12):1499-1507.

8. Litton E, Xiao J, Allen CT, Ho KM. Iron-restricted erythropoiesis and risk of red blood cell transfusion in the intensive care unit: a prospective observational study. Anaesth Intensive Care. 2015;43(5):612-616.

9. Dara SI, Rana R, Afessa B, Moore SB, Gajic O. Fresh frozen plasma transfusion in critically ill medical patients with coagulopathy. Crit Care Med. 2005;33(11):2667-2671.

10. Arnold DM, Crowther MA, Cook RJ, et al. Utilization of platelet transfusions in the intensive care unit: indications, transfusion triggers, and platelet count responses. Transfusion. 2006;46(8):1286-1291.

11. Spinelli E, Bartlett RH. Anemia and transfusion in critical care: physiology and management. J Intensive Care Med. 2016;31(5):295-306.

12. Litton E, Xiao J, Ho KM. Safety and efficacy of intravenous iron therapy in reducing requirement for allogeneic blood transfusion: systematic review and meta-analysis of randomised clinical trials. BMJ. 2013;347:f4822.

13. Arroliga AC, Guntupalli KK, Beaver JS, Langholff W, Marino K, Kelly K. Pharmacokinetics and pharmacodynamics of six epoetin alfa dosing regimens in anemic critically ill patients without acute blood loss. Crit Care Med. 2009;37(4):1299-1307.

14. Corwin HL, Gettinger A, Fabian TC, et al; EPO Critical Care Trials Group. Efficacy and safety of epoetin alfa in critically ill patients. $N$ Engl J Med. 2007;357(10):965-976.

15. Vincent JL, Spapen HD, Creteur J, et al. Pharmacokinetics and pharmacodynamics of once-weekly subcutaneous epoetin alfa in critically ill patients: results of a randomized, double-blind, placebo-controlled trial. Crit Care Med. 2006;34(6):1661-1667.

16. Gibbs MA. Ascorbic acid use in hyporesponders to Epoetin alfa. Nephrol Nurs J. 2000;27(4):413-415.

17. Pieracci FM, Stovall RT, Jaouen B, et al. A multicenter, randomized clinical trial of IV iron supplementation for anemia of traumatic critical illness. Crit Care Med. 2014;42(9):2048-2057.

18. IRONMAN Investigators, Litton E, Baker S, Erber WN, et al; Australian and New Zealand Intensive Care Society Clinical Trials Group. Intravenous iron or placebo for anaemia in intensive care: the IRONMAN multicentre randomized blinded trial: a randomized trial of IV iron in critical illness. Intensive Care Med. 2016;42(11):1715-1722. 
19. Bregman DB, Goodnough LT. Experience with intravenous ferric carboxymaltose in patients with iron deficiency anemia. Ther Adv Hematol. 2014;5(2):48-60.

20. Gong MN, Thompson BT, Williams P, Pothier L, Boyce PD, Christiani DC. Clinical predictors of and mortality in acute respiratory distress syndrome: potential role of red cell transfusion. Crit Care Med. 2005; 33(6):1191-1198.

21. Koch CG, Li L, Sessler DI, et al. Duration of red-cell storage and complications after cardiac surgery. $N$ Engl J Med. 2008;358(12):1229-1239.

22. Rosenbaum PR. Does a dose-response relationship reduce sensitivity to hidden bias? Biostatistics. 2003;4(1):1-10.

23. Hebert PC, Wells G, Blajchman MA, et al. A multicenter, randomized, controlled clinical trial of transfusion requirements in critical care. Transfusion requirements in critical care investigators, Canadian Critical Care Trials Group. New Engl J Med. 1999;340(6):409-417.

24. Lacroix J, Hébert PC, Hutchison JS, et al; TRIPICU Investigators; Canadian Critical Care Trials Group; Pediatric Acute Lung Injury and Sepsis Investigators Network. Transfusion strategies for patients in pediatric intensive care units. NEngl J Med. 2007;356(16):1609-1619.

25. Holst LB, Haase N, Wetterslev J, et al; TRISS Trial Group; Scandinavian Critical Care Trials Group. Lower versus higher hemoglobin threshold for transfusion in septic shock. NEngl J Med. 2014;371(15):1381-1391.

26. Alexander PE, Barty R, Fei Y, et al. Transfusion of fresher vs older red blood cells in hospitalized patients: a systematic review and metaanalysis. Blood. 2016;127(4):400-410.

27. Lacroix J, Hébert PC, Fergusson DA, et al; ABLE Investigators; Canadian Critical Care Trials Group. Age of transfused blood in critically ill adults. $N$ Engl J Med. 2015;372(15):1410-1418.

28. Robertson CS, Hannay HJ, Yamal JM, Gopinath S, Goodman JC, Tilley BC; Epo Severe TBI Trial Investigators. Effect of erythropoietin and transfusion threshold on neurological recovery after traumatic brain injury: a randomized clinical trial. JAMA. 2014;312(1):36-47.

29. Villanueva C, Colomo A, Bosch A, et al. Transfusion strategies for acute upper gastrointestinal bleeding. $N$ Engl J Med. 2013;368(1):11-21.

30. Jairath V, Kahan BC, Gray A, et al. Restrictive versus liberal blood transfusion for acute upper gastrointestinal bleeding (TRIGGER): a pragmatic, open-label, cluster randomised feasibility trial. Lancet. 2015;386(9989):137-144

31. Deans KJ, Minneci PC, Suffredini AF, et al. Randomization in clinical trials of titrated therapies: unintended consequences of using fixed treatment protocols. Crit Care Med. 2007;35(6):1509-1516.

32. de Almeida JP, Vincent JL, Galas FR, et al. Transfusion requirements in surgical oncology patients: a prospective, randomized controlled trial. Anesthesiology. 2015;122(1):29-38.

33. Docherty AB, O'Donnell R, Brunskill S, et al. Effect of restrictive versus liberal transfusion strategies on outcomes in patients with cardiovascular disease in a non-cardiac surgery setting: systematic review and metaanalysis. BMJ. 2016;352:i1351.

34. Hovaguimian F, Myles PS. Restrictive versus liberal transfusion strategy in the perioperative and acute care settings: a context-specific systematic review and meta-analysis of randomized controlled trials. Anesthesiology. 2016;125(1):46-61.

35. Perel P, Clayton T, Altman DG, et al; PROGRESS Partnership. Red blood cell transfusion and mortality in trauma patients: risk-stratified analysis of an observational study. PLoS Med. 2014;11(6):e1001664.

36. AlMomani T, Udaykumar HS, Marshall JS, Chandran KB. Micro-scale dynamic simulation of erythrocyte-platelet interaction in blood flow. Ann Biomed Eng. 2008;36(6):905-920.

37. Tutwiler V, Litvinov RI, Lozhkin AP, et al. Kinetics and mechanics of clot contraction are governed by the molecular and cellular composition of the blood. Blood. 2016;127(1):149-159.

38. Cines DB, Lebedeva T, Nagaswami C, et al. Clot contraction: compression of erythrocytes into tightly packed polyhedra and redistribution of platelets and fibrin. Blood. 2014;123(10):1596-1603.

39. Sihler KC, Napolitano LM. Complications of massive transfusion. Chest. 2010;137(1):209-220.
40. Ho KM, Litton E. Cost-effectiveness of using recombinant activated factor VII as an off-label rescue treatment for critical bleeding requiring massive transfusion. Transfusion. 2012;52(8):1696-1702.

41. Hoffman M, Monroe DM 3rd. A cell-based model of hemostasis. Thromb Haemost. 2001;85(6):958-965.

42. Ho KM, Pavey W. Applying the cell-based coagulation model in the management of critical bleeding. Anaesth Intensive Care. 2017;45(2): 166-176.

43. Johansson PI, Bochsen L, Stensballe J, Secher NH. Transfusion packages for massively bleeding patients: the effect on clot formation and stability as evaluated by Thrombelastograph (TEG). Transfus Apher Sci. 2008;39(1):3-8.

44. Johansson PI, Stensballe J, Rosenberg I, Hilsløv TL, Jørgensen L, Secher $\mathrm{NH}$. Proactive administration of platelets and plasma for patients with a ruptured abdominal aortic aneurysm: evaluating a change in transfusion practice. Transfusion. 2007;47(4):593-598.

45. Holcomb JB, Tilley BC, Baraniuk S, et al; PROPPR Study Group. Transfusion of plasma, platelets, and red blood cells in a 1:1:1 vs a 1:1:2 ratio and mortality in patients with severe trauma: the PROPPR randomized clinical trial. JAMA. 2015;313(5):471-482.

46. Stolla M, Refaai MA, Heal JM, et al. Platelet transfusion - the new immunology of an old therapy. Front Immunol. 2015;6:28.

47. Montoro-García S, Schindewolf M, Stanford S, Larsen OH, Thiele $\mathrm{T}$. The role of platelets in venous thromboembolism. Semin Thromb Hemost. 2016;42(3):242-251.

48. Blumberg N, Heal JM, Phillips GL. Platelet transfusions: trigger, dose, benefits, and risks. F1000 Med Rep. 2010;2:5.

49. Stanworth SJ, Estcourt LJ, Powter G, et al; TOPPS Investigators. A no-prophylaxis platelet transfusion strategy for hematologic cancers. N Engl J Med. 2013;368(19):1771-1780.

50. Estcourt L, Stanworth S, Doree C, et al. Prophylactic platelet transfusion for prevention of bleeding in patients with haematological disorders after chemotherapy and stem cell transplantation. Cochrane Database Syst Rev. 2012;5:CD004269.

51. Baharoglu MI, Cordonnier C, Al-Shahi Salman R, et al; PATCH Investigators. Platelet transfusion versus standard care after acute stroke due to spontaneous cerebral haemorrhage associated with antiplatelet therapy (PATCH): a randomised, open-label, phase 3 trial. Lancet. 2016;387(10038):2605-2613.

52. Kong R, Trimmings A, Hutchinson N, et al. Consensus recommendations for using the Multiplate ${ }^{\circledR}$ for platelet function monitoring before cardiac surgery. Int J Lab Hematol. 2015;37(2):143-147.

53. Rosengart TK, Romeiser JL, White LJ, et al. Platelet activity measured by a rapid turnaround assay identifies coronary artery bypass grafting patients at increased risk for bleeding and transfusion complications after clopidogrel administration. J Thorac Cardiovasc Surg. 2013;146(5):1259-1266.

54. Napolitano G, Iacobellis A, Merla A, et al. Bleeding after invasive procedures is rare and unpredicted by platelet counts in cirrhotic patients with thrombocytopenia. Eur J Intern Med. 2017;38:79-82.

55. Land WG. Transfusion-related acute lung injury: the work of DAMPs. Transfus Med Hemother. 2013;40(1):3-13.

56. Levy JH, Goodnough LT. How I use fibrinogen replacement therapy in acquired bleeding. Blood. 2015;125(9):1387-1393.

57. Levy JH, Welsby I, Goodnough LT. Fibrinogen as a therapeutic target for bleeding: a review of critical levels and replacement therapy. Transfusion. 2014;54(5):1389-1405.

58. Gando S, Hayakawa M. Pathophysiology of trauma-induced coagulopathy and management of critical bleeding requiring massive transfusion. Semin Thromb Hemost. 2016;42(2):155-165.

59. Steinmetz J, Sørensen AM, Henriksen HH, et al. Pilot randomized trial of fibrinogen in trauma haemorrhage (PRooF-iTH): study protocol for a randomized controlled trial. Trials. 2016;17(1):327.

60. Ranucci M, Baryshnikova E. Fibrinogen supplementation after cardiac surgery: insights from the Zero-Plasma trial (ZEPLAST). BrJAnaesth. 2016;116(5):618-623. 
61. Ho KM, Duff OC. Predictors of an increased in vitro thrombotic and bleeding tendency in critically ill trauma and non-trauma patients. Anaesth Intensive Care. 2015;43(3):317-322.

62. Stanworth SJ, Walsh TS, Prescott RJ, Lee RJ, Watson DM, Wyncoll D; Intensive Care Study of Coagulopathy (ISOC) investigators. A national study of plasma use in critical care: clinical indications, dose and effect on prothrombin time. Crit Care. 2011;15(2):R108.

63. De Pietri L, Bianchini M, Montalti R, et al. Thrombelastographyguided blood product use before invasive procedures in cirrhosis with severe coagulopathy: a randomized, controlled trial. Hepatology. 2016;63(2):566-573.

64. Whiting P, Al M, Westwood M, et al. Viscoelastic point-of-care testing to assist with the diagnosis, management and monitoring of haemostasis: a systematic review and cost-effectiveness analysis. Health Technol Assess. 2015;19(58):1-228.
65. Nelson A, Statkevicius S, Schött U, Johansson PI, Bentzer P. Effects of fresh frozen plasma, Ringer's acetate and albumin on plasma volume and on circulating glycocalyx components following haemorrhagic shock in rats. Intensive Care Med Exp. 2016;4(1):6.

66. Pati S, Matijevic N, Doursout MF, et al. Protective effects of fresh frozen plasma on vascular endothelial permeability, coagulation, and resuscitation after hemorrhagic shock are time dependent and diminish between days 0 and 5 after thaw. J Trauma. 2010;69 (Suppl 1):S55-S63.

67. Schött U, Solomon C, Fries D, Bentzer P. The endothelial glycocalyx and its disruption, protection and regeneration: a narrative review. Scand J Trauma Resusc Emerg Med. 2016;24:48.

68. Straat M, Müller MC, Meijers JC, et al. Effect of transfusion of fresh frozen plasma on parameters of endothelial condition and inflammatory status in non-bleeding critically ill patients: a prospective substudy of a randomized trial. Crit Care. 2015;19:163.
International Journal of Clinical Transfusion Medicine

\section{Publish your work in this journal}

International Journal of Clinical Transfusion Medicine is an international, peer-reviewed, open access, online journal publishing clinicalexperimental, policy-making and evidence-based practices of all topics pertaining to clinical transfusion medicine. Original research, short reports, reviews, case reports and commentaries are invited

\section{Dovepress}

The manuscript management system is completely online and includes a very quick and fair peer-review system, which is all easy to use. Visit http://www.dovepress.com/testimonials.php to read real quotes from published authors.

Submit your manuscript here: https://www.dovepress.com/international-journal-of-clinical-transfusion-medicine-journal 